\title{
EMOTIONAL SUPPORT FOR HEALTHCARE PROFESSIONALS CHILDREN: VIRTUAL INTERVENTION DURING COVID-19 PANDEMIC
}

\author{
Pedro Horta \\ Department of Psychiatry, Hospital Center of Vila Nova de Gaia/ Espinho pedro.horta@chvng.min-saude.pt \\ Ana Vera Costa \\ Department of Child and Adolescent Psychiatry, Hospital Center of Vila Nova de Gaia/ Espinho \\ ana.bessa.costa@chvng.min-saude.pt

\section{Sandra da Silva Mendes} \\ Department of Child and Adolescent Psychiatry, Hospital Center of Vila Nova de Gaia/ Espinho \\ sandra.mendes@chvng.min-saude.pt \\ Sofia Pires \\ Department of Child and Adolescent Psychiatry, Hospital Center of Vila Nova de Gaia/ Espinho \\ ana.rodrigues.pires@chvng.min-saude.pt \\ Sara Melo \\ Department of Child and Adolescent Psychiatry, Local Health Unit of Matosinhos. saramelo77@gmail.com \\ Joana Calejo Jorge \\ Department of Child and Adolescent Psychiatry, Hospital Center of Vila Nova de Gaia/ Espinho \\ joana.jorge@chvng.min-saude.pt

\section{Sandra Borges} \\ Department of Child and Adolescent Psychiatry, Hospital Center of Vila Nova de Gaia/ Espinho \\ sborges@chvng.min-saude.pt \\ Manuel Araújo \\ Department of Psychiatry, Hospital Center of Vila Nova de Gaia/ Espinho maraujo@chvng.min-saude.pt \\ Graça Mendes \\ Department of Child and Adolescent Psychiatry, Hospital Center of Vila Nova de Gaia/ Espinho \\ gmendes@chvng.min-saude.pt
}

Recepción Artículo: 17 julio 2021 Admisión Evaluación: 17 julio 2021 Informe Evaluador 1: 26 julio 2021

Informe Evaluador 2: 29 julio 2021 Aprobación Publicación: 30 julio 2021

\section{ACKNOWLEDGEMENTS}

The authors would like to gratefully acknowledge the work of Dr. Amy Saltzman who taught us the "Still Quiet Place" curriculum and gently brought our attention to the possibility of using Mindfulness-based techniques in children during a particularly difficult moment in their lives.

\section{CONFLICT OF INTERESTS}

The authors have declared no competing interests exist.

The authors have declared no external funding was received for this manuscrit. 


\title{
EMOTIONAL SUPPORT FOR HEALTHCARE PROFESSIONALS CHILDREN: VIRTUAL INTERVENTION DURING COVID-19 PANDEMIC
}

This research was approved by the Ethics Committee of the Hospital Center of Vila Nova de Gaia / Espinho. All participants gave verbal consent to group performance.

\begin{abstract}
Introduction: The SARS-CoV2 pandemic context and sanitary confinement measures have exposed the population to anxiety and depressive symptoms and became a permanent mark in children's psychosocial and affective development. This effect was certainly evident in healthcare professional's children that saw their parents being called to the battlefield front line against an invisible enemy and at the same time facing the media avalanche propelling fear and insecurity. Material and Methods: This state of restlessness and vulnerability promoted the development of therapeutic mindfulness groups for children or children and parents (healthcare professional related), from a Hospital Reference Center, over a period of eight weeks. Results: Throughout the sessions, high adherence to conscious attention techniques was observed, allowing the children to overcome physical distance obstacles in a virtual context used as a gateway to the living circumstances and the difficulties experienced at the time of the intervention. Discussion: In the end, improvements were reported in anxious and depressive symptoms with greater capacity for emotional regulation, interpersonal communication and impulse management. Conclusion: These results instigated an intervention protocol elaboration and a research project ongoing at the date of this publication.
\end{abstract}

Keywords: SARS-CoV-2; COVID-19; pandemic; children; healthcare professionals; mindfulness

\section{RESUMO}

Apoio emocional às crianças profissionais de saúde: intervenção virtual durante a pandemia de covid-19. Introdução: 0 contexto pandémico SARS-CoV2 e as medidas de confinamento tornaram a população vulnerável a sintomas ansiosos e depressivos e são um marco indelével no desenvolvimento psicossocial e afetivo das crianças. Tal foi notório nos filhos de profissionais de saúde, que perante a avalanche mediática propulsora de medo e insegurança, viram os seus progenitores ser chamados para a linha da frente de um campo de batalha contra um inimigo invisível. Material e Métodos: Este estado de inquietação e vulnerabilidade promoveu a elaboração de grupos terapêutico baseados no mindfulness para grupos de crianças (filhas de profissionais de saúde) de um Centro Hospitalar de referência, durante um período de oito semanas. Resultados: Participaram um total de quinze crianças e uma adolescente, sendo as crianças divididas em três grupos (dois grupos multifamiliares e um com crianças com idades entre oito e onze anos) e mantendo-se a adolescente em sessões individuais. Apenas uma criança não concluiu as oito sessões da terapia. Objetivou-se uma elevada adesão às técnicas de atenção plena e consciente, tendo sido transpostas as dificuldades impostas pelo distanciamento físico. A plataforma virtual foi usada como uma porta de acesso ao contexto vivencial e às dificuldades experienciadas no momento da intervenção. Discussão: No final foram reportadas melhorias na sintomatologia ansiosa e depressiva, com maior capacidade de regulação emocional, de comunicação interpessoal e gestão dos impulsos. Conclusão: Estes resultados promoveram a elaboração de um protocolo de intervenção e a realização de um projeto de investigação, em curso à data desta publicação.

Palavras-chave: Covid-19; SARS-CoV-2; crianças; profissionais de saúde; mindfulness

\section{INTRODUCTION}

The COVID-19 pandemic is leaving lasting marks not only on the physical health of the world population, but also on mental health. In the past, epidemics such as H1N1, MERS and SARS have shown a marked emotional rebound in the affected populations, and these effects have been particularly studied in the adult population. Although children are less susceptible to SARS-CoV2 infection, restrictive government measures, such as the closure of schools and kindergartens, as well as mandatory confinement, have had considerable psychological consequences concerning the children and families involved (Tsamakis K, 2020).

In fact, children's mental health can be strongly influenced by the COVID-19 pandemic, given that this context 
disaggregates the social fabric and the norms usually in effect, affecting normal emotional, cognitive and interpersonal development. Disruptive events such as the separation of family and friends, the existence of sick family members with whom one cannot have close physical contact and the sudden awareness of the mortality of beloved ones and themselves, predisposes children to the development of varied psychopathology namely anxiety disorders, depressive disorders or somatic symptom disorders as well as the worsening of pre-existing clinical conditions (Marques de Miranda D, 2020).

If the psychological impact of the measures adopted on children was mitigated in most of the population by the presence of parents or caregivers at home during the period of mandatory confinement, this did not happen in the families of professionals responsible for ensuring the functioning of the minimum services for the population. Of these, healthcare professionals stand out, who in the vast majority extended their working hours and were forced to stay away from their family. In view of the media avalanche, mandatory confinement and parental absence, it is possible to infer that children who were habitually cared for by health professionals and caregivers themselves are particularly vulnerable to the presence of anxious and depressive symptoms (Fegert JM, 2020).

The COVID-19 pandemic may, however, provide an opportunity to improve the scale and cost-effectiveness of different therapeutic approaches (Moreno C, 2020). In order to take advantage of this opportunity, it is necessary to rethink proximity care with users, promoting physical distance and not social distance, through the use of telepsychiatry (Cowan KE, 2019).

In order to fill the gaps arisen from lack of face-to-face contact, telemedicine and, in particular, telepsychiatry, have developed rapidly, with teleconsultation and videoconferencing being the most used strategies. Children, who were born and raised in the Internet age, seem to be even more permeable to the use of technology, even considering it as an instrument that facilitates the therapeutic relationship (Boydell KM, 2014).

In this context, we have developed a psychotherapeutic group with a view to providing emotional support care, supporting children and adolescents who face the same challenge - being the son/daughter of an indispensable health professional in the fight against SARS-CoV2 infection. Healthcare professionals from Hospital Center of Vila Nova de Gaia / Espinho (CHVNG/ E) were covered.

The practice of mindfulness, that is, the practice of awareness in the present moment, consciously and without judgment, becomes particularly challenging and necessary in the face of a pandemic, where the ability to stop and pay attention is, more than important, a necessity and a means of survival (Simkin DR, 2014). This practice, founded on ancient Buddhist traditions and with proven applications in programs such as MBSR (Mindfulnessbased Stress Reduction) or MBCT (Mindfulness-based Cognitive Therapy), has been used to treat anxiety disorders, depression, eating disorders, sleep disorders and addictive behaviors. More recently, studies have demonstrated the effectiveness of practices based on mindfulness in children and adolescents, namely in the control of attention and impulses as well as in the emotional regulation and reduction of anxious, depressive and disruptive behaviors (Thompson M, 2008). This intervention has also been associated with a decrease in functional somatic symptoms in adolescents. The literature shows promising results in the use of mindfulness concerning the disorders responsible for functional abdominal pain in children, such as irritable bowel syndrome, dyspepsia, abdominal migraine and functional abdominal pain - not otherwise specified (Santucci NR, 2020). The literature also demonstrates the effectiveness of these practices in Attention-Deficit/Hyperactivity Disorders as it has positive effects on components of the attention system and on the executive functions affected in this disorder (Evans $S, 2018)$. Neuroimaging studies concluded that the regular use of these techniques results in the activation of several brain structures, such as the prefrontal cortex, thalamus, and thalamic reticular nucleus, leading to a functional differentiation of the parietal lobe and resulting in a more focused mind. It also acts by enhancing the release of neurotransmitters, increasing parasympathetic activity and decreasing cortisol levels, contributing to its effectiveness in anxiety and mood disorders (Simkin DR, 2014).

There is also growing evidence and positive results from the use of mindfulness in parenting as an interventional technique to improve various dimensions of parenting and behavioral issues. Instituted programs (similar 
in effectiveness) demonstrated an improvement in the quality of the parent-youth relationship and an increase in empathic and compassionate concerns. They also promoted greater behavior management, enhancing parental well-being and self-regulation with reduced stress, applying parenting and family functioning strategies, all through breathing techniques and guided reflection (Coatsworth JD, 2015).

In the current pandemic situation, the impact of changes and routines at the family level stands out and the opportunity for virtual contact in the therapeutic aspect arises.

Bearing that in mind, the relevance of mindfulness practice in emotional regulation and the impulses of children and young people to face the physical and mental consequences of confinement and parental separation becomes clear.

\section{MATERIAL AND METHODS}

Through an institutional bulletin, we disseminated the Project to hospital professionals. It contained an accessible and easy registration form and we created an email exclusively dedicated to it in order to clarify doubts and support childhood mental health.

All children and adolescents enrolled in the Project were contacted and the parents were informed about the group functioning. The registrants were allocated according to the chronological age of the child / adolescent to groups consisting of children / adolescents or, in the case of enrolled children under the age of six, groups with children and parents (multifamily groups).

A total of sixteen children of health professionals, aged between three and fifteen years old, enrolled in the project. Two multifamily groups were created with children of preschool age (with four elements each) and a group composed of children aged between eight and eleven years old (with seven elements), with parental supervision only in the first and penultimate session. All sessions with the described groups were carried out in co-therapy, all elements being trained in cognitive-behavioral therapy, and at least one of the therapists having specialized training in the applied program.

The group had fifteen-year-old girl signing up, and since there were no other registrations in the same age group, we chose, in this case, to adapt the program to an individual format, only with a therapist.

Before the beginning of the intervention, we conducted a semi-structured interview in order to evaluate psychopathology. Based on this interview, seven children were identified with the following clinical conditions - diagnoses according to the Diagnostic Classification of Mental Health and Developmental Disorders of Infancy and Early Childhood - DC 0-5 (2018) and the Diagnostic and Statistical Manual of Mental Disorders - DSM-5 (APA, 2013) - one Encopresis, one Somatic Symptom Disorder with Comorbid Anxiety Disorder, two Regulatory Disorders of Sensory Processing, two Social Anxiety Disorders with Performance Specificity, and two AttentionDeficit/Hyperactivity Disorders. The intervention was not altered by the clinical picture presented, allowing only to ascertain the characteristics and heterogeneity of the groups and respective members.

The intervention was inspired by the Mindfulness Program "A Still Quiet Place" (Saltzman, 2020) - with proper authorization of the author - that seeks to teach children and adolescents to deal with anxiety and difficult emotions.

In the most acute context of the pandemic, considering the Directorate-General of Health and the restrictions imposed on citizens, the use of information and communication technologies proved to be essential in accessing children, adolescents and their families. The sessions were held by videoconference, in online-live sessions, through the Zoom platform. The Program was developed over eight psychotherapeutic sessions, with a weekly frequency and duration of approximately 60 minutes each.

According to the adopted mindfulness program, we have implemented psychotherapeutic techniques such as sharing personal experiences, role-plays, mindfulness practices and self-compassion. Some of the themes covered during the sessions were: pleasant and unpleasant day-to-day events, the basic theory of emotions, "equation of pain and suffering", observation of the "restless mind", differences between "responding" and "reacting", difficult intra-family communication, kindness and self-compassion. 
In addition to the group sessions, we often contacted children and parents using email, sending weekly audio practices and self-recording emotions, thoughts and behaviors. The set of techniques used has scientific evidence in providing adaptive coping mechanisms, promoting cognitive functions (namely cognitive flexibility, attention and impulse control) and predisposes to self-efficacy in emotional regulation.

In the case of intense and disruptive symptomatology during the eight weeks of the Program or in the reassessment after its completion, guidance for individualized support was provided using the consultation of Child and Adolescent Psychiatry.

The project was validated by the Ethics Committee of Hospital Center Vila Nova de Gaia / Espinho. All participants gave verbal consent to group performance.

\section{RESULTS}

A satisfactory adhesion to the Project was evident, with the participation of 16 children and adolescents. Furthermore, there were several contacts to clarify doubts.

The investment in the sessions, commitment to sharing and experimenting with pleasant fulfillment of the multiple proposed exercises was transversal to all groups.

In the evaluation interviews after group completion, signs of a good adaptation to stress and reduction of anxiety were visible, consistent with the results of the research carried out in the original Program (Saltzman, 2020).

Throughout the therapeutic intervention, parents provided feedback on the application of the exercises throughout the week, identifying in their children, in general, the stimulation of a curious mind, with an increase in emotional recognition and management as well as in social capacities. According to parents, the groups made it possible to foster emotion sharing, active communication and the reduction of perceived anxiety. There was also a subjective improvement in the quality and quantity of the participants' sleep. Both children and caregivers expressed a desire to continue their practice after the end of the 8 sessions and considered that the therapy proved to be useful in relieving symptoms in children presenting psychopathology (namely symptoms of anxiety and attention deficit).

\section{DISCUSSION}

\section{Virtual experience}

Regarding the assessment by therapists, the virtual context presented some limitations, mainly in the initial stages, when it was challenging to capture the children's attention and motivate them to practice. Assertiveness was also sometimes compromised, in the first sessions, making communication increasingly fluid with experimentation, developing familiarity with the platform and time management of activities, with intervals between exercises.

On the other hand, the virtual context allowed for the sharing of creative mindful activities through image, music and video content. With this approach, it was possible to "go into the homes" of families, who were available to illustrate their routines and difficulties or achievements, in a particularly demanding stage of their lives. This vulnerability became the engine of sharing and reporting more or less mindful experiences, which worked as a backdrop for multiple sessions.

Framed at the time and context of the pandemic we face, this experience is regarded by the therapists who carried out this multifamily groups as providing a closer approach to families, with a more intimate view of its functioning and asserting its characteristics as a system in the face of the adverse experiential context.

\section{Children group}

The group of children aged between eight and eleven years was the one with the most elements (total of seven) and which was particularly challenging because it was devoid of the presence of caregivers in most sessions. The use of the Zoom platform in virtual classes made these children particularly knowledgeable about the 
technology used and experienced some complications, namely the contact via chat between some elements (which was, when perceived, not possible) or alteration of the image and sound emitted (by altering the sound and image settings or disabling the image emission through cloth or fingers). These behaviors were registered more predominantly in children without verifiable psychopathology. The therapists' approach was to point out some of these behaviors as "mindless" moments avoiding criticism and hostility, and to use some of the tools of mindfulness to address them (namely the differences between "responding" and "reacting" and the use of metaphors). Also, delays with interruption of the session for each new participant entry as well as the difficulty in maintaining privacy (one of the participants tried to log in while on the beach) were negative points registered during the sessions. As a way of avoiding these constraints, in the first session a verbal agreement was made with each member of the group, addressing the importance of confidentiality, punctuality and respectful behavior, which was reminded during intercurrences.

Progressively, the group became more involved with a growing attentive curiosity in the exercises performed. The degree of intellectual development of the group made it possible to work on more abstract ideas than with multifamily groups, namely restless thinking, the embodiment of emotions and metacognition. The practice allowed therapists and children to speak truthfully and honestly about their experiences, namely the anguish and difficulties associated with the pandemic context, in a place that they considered safe and non-judgmental. During the activities, one of the elements compared a restless mind to a "poisonous snake" and this metaphor was used progressively throughout the sessions and with different groups. The metaphor's rich imagery allowed for a greater understanding of the contents and a greater involvement of all elements. In contacts via email, it was possible to perceive a growing interest in audio recordings (in children with Attention-Deficit/Hyperactivity Disorder they were used by themselves several times a day, with positive results in what concerns controlling impulsivity and increasing perceived attention). Of the seven elements, there was only one withdrawal due to clinical reasons and was oriented for consultation. At the end of the sessions, most members of the group who remained in therapy expressed a wish to continue their practice autonomously, reiterating the benefit of practices in their day-to-day lives, especially in times of greatest conflict and anxiety. The virtual context has also become a way of approaching the living context of each child, with a clearer perception of the difficulties they faced in a context of confinement. For the authors, the work with this group proved to be enriching, both in the establishment of an online therapeutic dynamics and in the observation in loco (outside the usual therapeutic setting) of impulse control difficulties, disruptive behaviors and difficulty in dealing with painful emotions. Of the six patients who finished the group, four were followed up in individual consultations in Child and Adolescent Psychiatry.

\section{Multifamily groups}

Multifamily groups consisted of eight children aged between three and six and their parents. This family approach became very rich, as it was possible to work with children, but also with their parents, with an impact on all the elements involved and on the family system. There was an active collaboration of the parents in carrying out the exercises proposed by the therapists, intervening as a facilitators and mediators, both during sessions and in carrying out daily practices. Parents present at the session were not only invited to monitor their children, but also to do the proposed exercises, providing, at the same time, pleasant family moments and a therapeutic approach, which culminated in improving the relationship between parents and children. For the therapists, it was stimulating to feel how enthusiastically they were welcomed by the children through the screens at each session during the confinement period, thus reducing the impact of isolation.

Taking into account the cognitive development of children of this age, we tried to work on simpler and more concrete concepts, such as the identification of basic emotions, with the respective recognition in themselves and in others, and association of emotions with bodily events and sensations.

The children adhered particularly well to breathing, meditation and movement exercises, and there were several occasions when they even asked to repeat the exercise. 
Throughout the sessions, children's spontaneity was lovely and captivating, but also challenging, as they more easily mirrored their displeasure and tiredness in the task. Therefore, there was the need for more dynamic exercises and with greater rotation. Several challenges arose throughout the sessions, leading therapists to constantly deal with the unpredictability of the moment and to be guided by the children's behavior. In one of the first sessions, in one of the "eating consciously" exercises, one of the children refused to eat the orange suggested by the therapists, simply because she did not like it. In that same exercise, another child with sensory processing disorder had great difficulties in carrying it out, as she had an aversion to the orange texture; however, there was an evident improvement in her symptoms, with the practice being performed in a more fluid and satisfactory way throughout the sessions.

During the week, they were asked to do a daily mindfulness practice and an exercise to work on emotional knowledge. The children shared the exercises in the following sessions, usually in the form of drawings, with great enthusiasm. It was evident an increasing sharing of everyday experiences and important events, with a greater recognition of sensations and associated feelings. The most pleasant experiences brought by the children were about the favorite games, the relationship with the different elements of the family, specifically parents and / or siblings, friends from school and the existence of pets. They were also asked to share unpleasant experiences and emotions. One of the children shared, when exploring unpleasant experiences, the event of her cat's death. On the other hand, through this sharing, another child immediately picked up her cat to show it to the others, which was a situation difficult for therapists to manage, but of enormous richness, for the children's reading and emotional sharing.

Throughout the sessions, the introduction of the concept of mindfulness in the daily lives of these children grew, in a more spontaneous and intuitive way. They reported that, when eating, they paid attention to body movements and sensations, and did this more slowly; the same happened in the moments of hygiene. Two of the children, who were brothers, shared with the therapists, with great enthusiasm and pleasure, how they made going to the beach with their father a more conscious and complete experience from an emotional point of view, recreating exercises from the sessions, namely "walking consciously" on the sand and a breathing exercise in the waves of the sea. In the final stage of the sessions, the country was no longer in general confinement, thus allowing for a greater range of experiences for families, giving them the opportunity to practice and share more experiences and sensations. This sharing proved to be an indicator of trust, involvement and commitment in this process and method of intervention.

\section{Therapeutic projects}

This pilot project created in a pandemic context made it possible to carry out a clinical protocol taking place in the Outpatient Clinic of our medical center and the formulation of an quasi-experimental study targeting children between seven and seventeen years old, with the objective of evaluating therapeutic intervention. Thus, before the intervention and six months afterwards, the participants will be invited to fill out instruments for the evaluation of symptoms and functioning, validated for the Portuguese population.

\section{CONCLUSION}

The SARS-CoV2 pandemic context has led to abrupt and unexpected changes in the daily lives of children and young people, and the impact on mental health in the medium and long term has yet to be estimated. The physical distance opposed by the need for social involvement set the tone for virtual psychotherapeutic interventions and, in the case of our project, allowed us to intervene in a particularly vulnerable group such as the children of healthcare professionals. To our knowledge, as of the date of this article, this is the first study focused on the impact of the COVID-19 pandemic on the children of health professionals and the benefit of the intervention based on mindfulness addressing them. This intervention proved to be particularly useful due to the evidence in the improvement of anxious and depressive symptoms, which may arise from the existence of a pandemic state and 
also due to the easy applicability and well-established doctrinal roots. The promotion of multifamily groups has also allowed for an intervention at a systemic and family level, which addressed some difficulties that individual interventions do not enable. This intervention may be of particular importance in Primary Prevention at the level of Primary Health Care and Schools, since it proves to be a cost-effective means of support, quick and easy to implement, with good results in improving attention control, emotional and behavioral regulation, helping prevent multiple pathologies in the area of mental health.

Despite the technical and methodological difficulties already described, therapists reported an important subjective improvement in anxious and depressive symptoms in most of the participants. These good results boosted a Project to implement the Program at the Outpatient Clinic of our medical center, in order to respond to users attending the Child and Adolescent Psychiatry consultation, currently approved by the Service Directorate.

In view of the evolution of the pandemic, the possible repetition of the Project in the same target group, children of health professionals involved in fighting COVID-19, is being considered.

\section{BIBLIOGRAPHIC REFERENCES}

American Psychiatric Association. (2013). Diagnostic and statistical manual of mental disorders (5th ed.). https://doi.org/10.1176/appi.books.9780890425596

Saltzman, A. (2014). A still quiet place. A mindfulness program for teaching children and adolescents to ease stress and difficult emotions. Oakland: New Harbinger.

Boydell KM, Hodgins M, Pignatiello A, Teshima J, Edwards H, Willis D. Using technology to deliver mental health services to children and youth: a scoping review. J Can Acad Child Adolesc Psychiatry. 2014;23(2):87-99.

Coatsworth JD, Duncan LG, Nix RL, Greenberg MT, Gayles JG, Bamberger KT, et al. Integrating mindfulness with parent training: effects of the Mindfulness-Enhanced Strengthening Families Program. Dev Psychol. 2015;51(1):26-35 https://doi.org/10.1037/a0038212

Cowan KE, McKean AJ, Gentry MT, Hilty DM. Barriers to Use of Telepsychiatry: Clinicians as Gatekeepers. Mayo Clin Proc. 2019;94(12):2510-2523. https://doi.org/10.1016/j.mayocp.2019.04.018

DC: 0-5: Diagnostic Classification of Mental Health and Development disorders of infancy and early childhood. Infant Mental Health Journal. 1st edition. 2018.

Evans S, Ling M, Hill B, Rinehart N, Austin D, Sciberras E. Systematic review of meditation-based interventions for children with ADHD. Eur Child Adolesc Psychiatry. 2018;27(1):9-27. https://doi.org/10.1007/s00787017-1008-9

Fegert JM, Vitiello B, Plener PL, Clemens V. Challenges and burden of the Coronavirus 2019 (COVID-19) pandemic for child and adolescent mental health: a narrative review to highlight clinical and research needs in the acute phase and the long return to normality. Child Adolesc Psychiatry Ment Health. 2020;14:20

https://doi.org/10.1186/s13034-020-00329-3

Marques de Miranda D, da Silva Athanasio B, Sena Oliveira AC, Simoes-E-Silva AC. How is COVID-19 pandemic impacting mental health of children and adolescents? Int J Disaster Risk Reduct. 2020;51:101845. https://doi.org/10.1016/j.ijdrr.2020.101845

Moreno C, Wykes T, Galderisi S, Nordentoft M, Crossley N, Jones N, et al. How mental health care should change as a consequence of the COVID-19 pandemic. Lancet Psychiatry. 2020;7(9):813824. https://doi.org/10.1016/S2215-0366(20)30307-2

Santucci NR, Saps M, van Tilburg MA. New advances in the treatment of paediatric functional abdominal pain disorders. Lancet Gastroenterol Hepatol. 2020;5(3):316-328.

https://doi.org/10.1016/S2468-1253(19)30256-0

Simkin DR, Black NB. Meditation and mindfulness in clinical practice. Child Adolesc Psychiatr Clin N Am. 2014 Jul;23(3):487-534. https://doi.org/10.1016/j.chc.2014.03.002

Thompson M, Gauntlett-Gilbert J. Mindfulness with children and adolescents: effective clinical application. Clin 
APRENDIENDO EN POSITIVO: SUPERANDO EL COVID

Child Psychol Psychiatry. 2008 Jul;13(3):395-407

https://doi.org/10.1177/1359104508090603

Tsamakis K, Rizos E, Manolis AJ, Chaidou S, Kympouropoulos S, Spartalis E, et al. COVID-19 pandemic and its impact on mental health of healthcare professionals. Exp Ther Med. 2020;19(6):3451-3453. https://doi.org/10.3892/etm.2020.8646 
